\title{
Quail Fibrosarcoma
}

National Cancer Institute

\section{Source}

National Cancer Institute. Quail Fibrosarcoma. NCI Thesaurus. Code C134950.

Fibrosarcoma that occurs in a quail. 